\title{
Application of Membrane-Based Preferential Transport to Whole Broth Processing
}

\author{
Akhil Agrawal,* Mark A. Burns \\ Department of Chemical Engineering, The University of Michigan, Ann \\ Arbor, Michigan 48109-2136; telephone: 313-764-4315; fax: 313-763-0459; \\ e-mail:maburns@umich.edu
}

Received 23 February 1996; accepted 1 November 1996

\begin{abstract}
Preferential transport in adsorptive membranes can be used to selectively remove biochemicals directly from fermentation broths. During preferential transport, an adsorbing solute is selectively transported across the membrane while nonadsorbing solutes and cells are retained by the membrane. This technique was used to separate lysozyme directly from a feed containing lysozyme, myoglobin, and yeast cells. We found that because the oscillatory flows used in preferential transport involve strokes that are close to symmetric, they are very efficient in alleviating cake formation due to cell deposition on the membrane surface. Theoretical results suggest that, by optimizing process variables, preferential transport can lead to a continuous concentrated stream of the adsorbing protein. (c) 1997 John Wiley \& Sons, Inc. Biotechnol Bioeng 55: 581-591, 1997.
\end{abstract}

Keywords: adsorptive membranes; oscillatory flow; integrated processes; in situ product recovery

\section{INTRODUCTION}

In situ product removal (ISPR), the removal of a biochemical product from the vicinity of a cell as it is being produced by that cell, can be advantageous in a number of situations. For example, ISPR can be used to continuously remove a toxin that either inhibits cell growth or degrades an extracellular product. Additionally, ISPR could be employed for the removal of a product that is labile in a cell broth or exhibits feedback regulation on product yield. Freeman et al. (1993) pointed out that there is a need for further development of ISPR techniques for the recovery of high molecular weight products such as proteins.

An integrated separation process that combines cell separation (microfiltration) and selective solute separation (ion exchange, affinity, etc.) can be used for ISPR. In previous studies (Agrawal and Burns, 1996a,b) we proposed that one of the two separation modes of recu-

\footnotetext{
*Present address: Merck \& Co., Inc., P.O. Box 4, WP28-70, West Point, PA 19486.

Correspondence to: M. A. Burns

Contract grant sponsor: National Science Foundation

Contract grant numbers: CTS-9216078 and CTS-9096185

Contract grant sponsor: University of Michigan
}

perative parametric pumping (Grevillot, 1986; Huang and Hollein, 1988; Sweed and Rigaudeau, 1975; Wankat, 1978; Wilhelm et al., 1966) can be used to selectively remove one solute from a solution containing many solutes. If an oscillatory flow is used in conjunction with a macroporous adsorptive membrane, selective or preferential transport of the adsorbing species can occur through the membrane. Nonadsorbing solutes are rejected by the membrane along with particles larger than the membrane's pore size. The mechanism of cell rejection is simple filtration while the rejection of nonadsorbing solutes is due to the cyclical convective flow.

The separation of the adsorbing solute from a nonadsorbing solute during preferential transport is shown in Figure 1. In the first half of a cycle, an adsorbing solution containing an adsorbing solute, $A$, and a nonadsorbing solute, $B$, is fed into the membrane. During this halfcycle, $A$ adsorbs to the surface of the membrane while $B$ remains in the membrane void. In the second half of the cycle, a solute-free desorbing solution is fed into the membrane in the reverse direction. In this half-cycle, $B$ is transported back to the membrane's left side while $A$ desorbs but stays within the interior of the membrane. This desorbed $A$ is transported across the membrane in the first half of the next cycle. In this way, the nonadsorbing solute is "rejected" by the membrane while the adsorbing solute is preferentially transported through the membrane.

Our previous studies on preferential transport focused on studying the separation of an adsorbing protein from a nonadsorbing protein in a semicontinuous apparatus. However, preferential transport has the potential of continuously removing a protein from a feed containing not only other solutes but also suspended particles. A continuous separation system can be constructed using two stirred reservoirs separated by an adsorptive membrane stack (Fig. 2). In such a configuration, the oscillatory flow exposes the membrane to alternately adsorbing and desorbing conditions, leading to separation as described in Figure 1. The oscillatory flows used in this type of separation have the added advantage of alleviating the cake formation and decreased permeate 
Adsorbing Solution

\section{Adsorbing} Solution

\section{Adsorbing Solution}

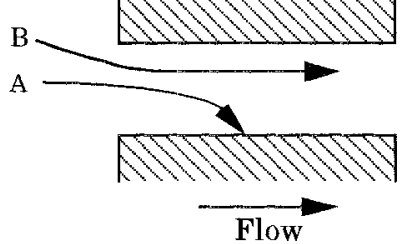

Second Half of a Cycle

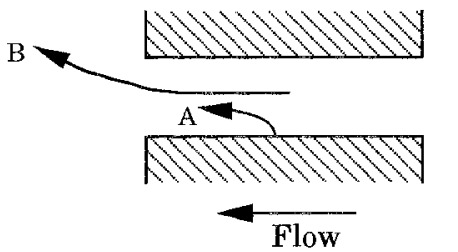

First Half of the Next Cycle

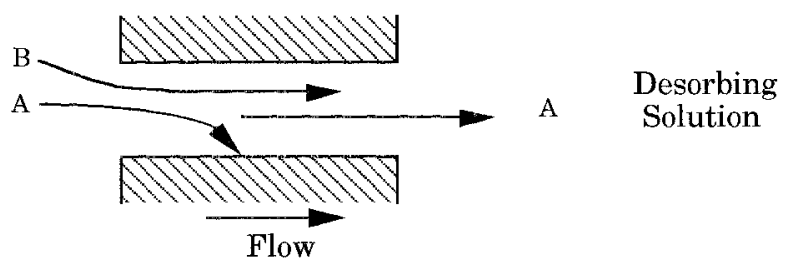

Desorbing

Solution

Desorbing

Solution
Flow

Figure 1. Preferential transport in an adsorptive membrane. In the first half of a cycle, the adsorbing solute $A$ adsorbs to the membrane surface while the nonadsorbing solute $B$ remains in the membrane void. In the second half of the cycle, $B$ is "rejected" by the membrane while $A$ desorbs but stays within the desorption front. In the first half of the next cycle, this desorbed $A$ is preferentially transported across the membrane.

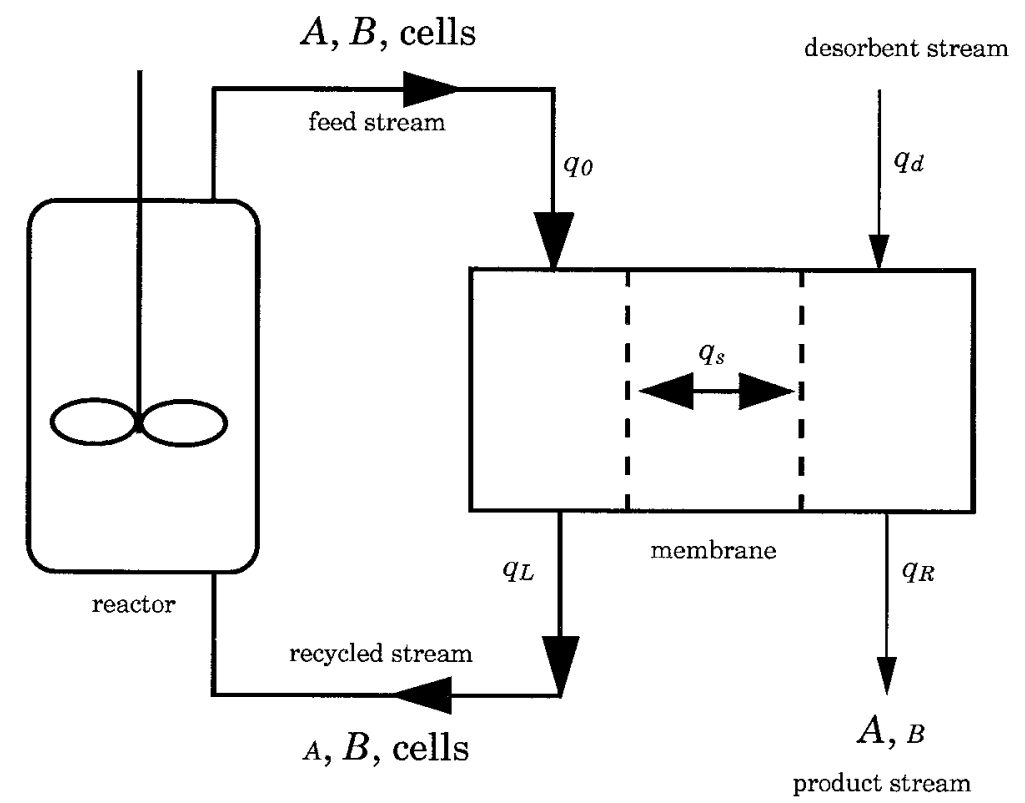

Figure 2. Proposed configuration for in situ product recovery using preferential transport. Using preferential transport through adsorptive membranes, an adsorbing solute $A$ can be selectively and continuously removed from a feed containing cells and other nonadsorbing contaminants such as $B$. The oscillatory flow used to accomplish preferential transport performs a dual role. First it generates alternating adsorbing and desorbing conditions for the selective transport of $A$ through the membrane; second it causes turbulence close to the membrane surface and alleviates cake formation. 
flux typically encountered when processing cell suspensions (Belfort, 1989; Kroner et al., 1984; Matsumoto et al., 1987; Redkar and Davis, 1995).

The purpose of this study was to determine the effect of suspended cells in the feed stream on the performance of a continuous protein recovery system based on preferential transport. We experimentally investigated the effect of oscillatory flows on the filtration of suspended cells. We analyzed a continuous selective separation system, experimentally and mathematically, and determined the key parameters that influence the performance of such a device.

\section{MATHEMATICAL MODEL}

The model consists of internal mass balances (mass balances within the membrane) and external mass balances (mass balances on the continuous contactor).

\section{Internal Mass Balances}

The internal mass balances for recuperative parametric pumping in adsorptive membranes were presented in detail elsewhere (Agrawal and Burns, 1996a) and will be discussed only briefly in this section. In the model, the membrane is considered to be isothermal and homogeneous with a uniform cross-sectional area, $A$, porosity, $\varepsilon$, and thickness, $L$. The mass balances of a solute, $i$, and of the desorbent, $d$ (if the adsorption of the desorbent onto the membrane is negligible), for the adsorbing stroke (first half of a cycle) are given by Equations (1) and (2), respectively.

$$
\begin{aligned}
\frac{\partial C_{i}}{\partial t}+\frac{1}{\varepsilon} \frac{\partial Q_{i}}{\partial t} & =E_{i} \frac{\partial^{2} C_{i}}{\partial^{2} l}-u_{\mathrm{a}} \frac{\partial C_{i}}{\partial l}, \\
\frac{\partial C_{\mathrm{d}}}{\partial t} & =E_{\mathrm{d}} \frac{\partial^{2} C_{\mathrm{d}}}{\partial^{2} l}-u_{\mathrm{a}} \frac{\partial C_{\mathrm{d}}}{\partial l},
\end{aligned}
$$

where $C_{i}$ and $Q_{i}$ are the concentrations of the species $i$ in the pore and on the surface, respectively; $C_{\mathrm{d}}$ is the concentration of the desorbent in the pore, $E_{i}$ and $E_{\mathrm{d}}$ are the axial dispersion coefficients for species $i$ and desorbent, respectively; and $u_{\mathrm{a}}$ is the interstitial velocity during the adsorbing stroke. The mass balances for the desorbing stroke are also given by Equations (1) and (2), except that the velocity during the adsorbing stroke, $u_{\mathrm{a}}$, is replaced by the velocity during the desorbing stroke, $u_{\mathrm{d}}$, and the dispersion coefficients are evaluated at $u_{\mathrm{d}}$.

If local equilibrium is assumed and multicomponent effects are neglected (both reasonable assumptions; Agrawal and Burns, 1996a), the concentrations of the species $i$ in the pore, $C_{i}$, and on the surface, $Q_{i}$, can be related using single component Langmuir isotherms obtained at various desorbent concentrations. Such a Langmuir isotherm formalism is given by

$$
Q_{i}=\frac{Q_{m, i} K_{m, i} C_{i}}{1+K_{m, i} C_{i}}
$$

where the adsorbent capacity, $Q_{m, i}$, and equilibrium constant, $K_{m, i}$, are functions of the desorbent concentration. These functions can be written (Antia and Horvath, 1989) as

$$
\begin{aligned}
& K_{m, i}=K_{m, i}^{\max } f\left(C_{\mathrm{d}}\right), \\
& Q_{m, i}=Q_{m, i}^{\max } g\left(C_{\mathrm{d}}\right),
\end{aligned}
$$

where $C_{\mathrm{d}}$ is the concentration of the desorbent, $K_{m, i}^{\max }$ and $Q_{m, i}^{\max }$ are the values of equilibrium constant and membrane capacity of solute $i$, respectively, at zero desorbent concentration, and $f$ and $g$ are experimentally determined functions.

Equations (1)-(4), combined with the appropriate initial and boundary conditions, were dedimensionalized and yielded the following dimensionless parameters: $\alpha_{i}=K_{m, i}^{\max } C_{i, 0}$, which is the isotherm linearity parameter for species $i ; \delta_{i}=Q_{m, i}^{\max } / \varepsilon C_{i, 0}$, which is the dimensionless membrane capacity for species $i$; and $\mathrm{Pe}_{i}=u_{\mathrm{a}} L / E_{i}$, which is the Peclet number for species $i$.

\section{External Mass Balances}

First the volumetric balances are given in Equations (5)-(10) followed by the mass balances in Equations (11)-(14). Next, the reservoir volumes that vary with time due to the oscillatory flow are mathematically described in Equations (15)-(18). Finally, the key dimensionless parameters that form the basis of design are given; design results are presented in the next section.

The oscillatory flow in the continuous contactor is given by

$$
q_{\mathrm{s}}=\eta V_{\mathrm{s}},
$$

where $\eta$ is the frequency of oscillations and $V_{\mathrm{s}}$ is the stroke volume. As we mentioned in earlier studies (Agrawal and Burns, 1996a,b), an asymmetric oscillatory flow is required for optimal separations. Such an asymmetric flow can be obtained by superimposing a net convective flux $\left(q_{\mathrm{c}}\right)$ through the membrane on top of the oscillatory flow. The magnitude of the net convective flux is obtained from the value of the ratio of the adsorbing stroke volume to the desorbing stroke volume $\left(V_{\mathrm{s}, \mathrm{a}} / V_{\mathrm{s}, \mathrm{d}}\right)$.

$$
q_{\mathrm{c}}=q_{\mathrm{s}}\left(\frac{\frac{V_{\mathrm{s}, \mathrm{a}}}{V_{\mathrm{s}, \mathrm{d}}}-1}{\frac{V_{\mathrm{s}, \mathrm{a}}}{V_{\mathrm{s}, \mathrm{d}}}+1}\right) .
$$

After fixing the value of $q_{\mathrm{c}}$, the flow rates are all fixed by simple volumetric balances given by the following equations:

$$
\begin{aligned}
& q_{\mathrm{s}, \mathrm{a}}=q_{\mathrm{s}}+q_{\mathrm{c}}, \\
& q_{\mathrm{s}, \mathrm{d}}=q_{\mathrm{s}}-q_{\mathrm{c}},
\end{aligned}
$$




$$
\begin{gathered}
q_{\mathrm{L}}=q_{0}-q_{\mathrm{c}}, \\
q_{\mathrm{R}}=q_{\mathrm{D}}+q_{\mathrm{c}},
\end{gathered}
$$

where $q_{0}, q_{\mathrm{D}}, q_{\mathrm{L}}$, and $q_{\mathrm{R}}$ are the flow rates of feed, desorbent, left product, and right product streams, respectively.

After determining the volumetric flow rates, the following mass balances are solved. Note that the mass balances change for each half-cycle because the direction of flow is reversed. Mass balances during the adsorbing stroke for the left and the right reservoirs, respectively, are given by

$$
\begin{array}{r}
C_{i, 0} q_{0}-C_{i, \mathrm{~L}} q_{\mathrm{L}}-C_{i, \mathrm{~L}} q_{\mathrm{s}, \mathrm{a}}=\frac{\partial V_{\mathrm{L}} C_{i, \mathrm{~L}}}{\partial t}, \\
C_{i, \mathrm{D}} q_{\mathrm{D}}-C_{i, \mathrm{R}} q_{\mathrm{R}}+C_{i}(z=L) q_{\mathrm{s}, \mathrm{a}}=\frac{\partial V_{\mathrm{R}} C_{i, \mathrm{R}}}{\partial t},
\end{array}
$$

where $C_{i, 0}, C_{i, \mathrm{D}}, C_{i, \mathrm{~L}}$ and $C_{i, \mathrm{R}}$ are the concentrations of solute $i$ in the feed, desorbent, left product, and right product, respectively, and $V_{\mathrm{L}}$ and $V_{\mathrm{R}}$ are the volumes of the left and the right reservoirs, respectively. Similarly, mass balances during the desorbing stroke for the respective left and the right reservoirs are given by

$$
\begin{aligned}
C_{i, 0} q_{0}-C_{i, \mathrm{~L}} q_{\mathrm{L}}+C(z=0) q_{\mathrm{s}, \mathrm{d}} & =\frac{\partial V_{\mathrm{L}} C_{i, \mathrm{~L}}}{\partial t}, \\
C_{i, \mathrm{D}} q_{\mathrm{D}}-C_{i, \mathrm{R}} q_{\mathrm{R}}-C_{i, \mathrm{R}} q_{\mathrm{s}, \mathrm{d}} & =\frac{\partial V_{\mathrm{R}} C_{i, \mathrm{R}}}{\partial t} .
\end{aligned}
$$

The sum of the reservoir volumes at a given time is fixed; however, the individual reservoir volumes, $V_{\mathrm{L}}$ and $V_{\mathrm{R}}$, vary with time. For example, during the adsorbing stroke, solution flows from the left reservoir to the right reservoir and so $V_{\mathrm{L}}$ decreases while $V_{\mathrm{R}}$ increases. It is important to note that the reservoir volumes do not change from one cycle to the next even though they change within each cycle. If the pump that generates the oscillatory flow gives rise to a square wave and the oscillations start with an adsorbing stroke, then the reservoir volumes during the adsorbing stroke are given by

$$
\begin{aligned}
& V_{\mathrm{L}}=V_{\mathrm{L}}^{0}-q_{\mathrm{s}} t, \\
& V_{\mathrm{R}}=V_{\mathrm{R}}^{0}+q_{\mathrm{s}} t,
\end{aligned}
$$

where $V_{\mathrm{L}}^{0}$ is the initial volume of the left reservoir and $V_{\mathrm{R}}^{0}$ is the initial volume of the right reservoir. Similarly, the reservoir volumes during the desorbing stroke are given by

$$
\begin{gathered}
V_{\mathrm{L}}=V_{\mathrm{L}}^{0}-q_{\mathrm{s}}\left(T_{\mathrm{c}} / 2-t\right), \\
V_{\mathrm{R}}=V_{\mathrm{R}}^{0}+q_{\mathrm{s}}\left(T_{\mathrm{c}} / 2-t\right) .
\end{gathered}
$$

The key dimensionless parameters that emerge after dedimensionalization of Equations (5)-(18) are: $q_{\mathrm{s}} / q_{0}$ is the ratio of oscillatory flow to feed flow, $q_{\mathrm{d}} / q_{0}$ is the ratio of desorbent flow to feed flow, $V_{\mathrm{L}}^{0} / V_{\mathrm{m}}$ is the ratio of initial left reservoir volume to membrane void volume, and $V_{\mathrm{R}}^{0} / V_{\mathrm{m}}$ is the ratio of initial right reservoir volume to membrane void volume.

Equations (1)-(18) were solved using finite difference techniques with the appropriate boundary conditions. Note that all parameters used in the model were determined independently.

\section{MATERIALS}

Lysozyme (L 6876), myoglobin (M 1882), Saccharomyces cerevisiae (Bakers Yeast, YSC-2), and sodium azide (S 2002) were purchased from Sigma Chemical Company (St. Louis, MO). Potassium chloride (304001 ), dibasic anhydrous sodium phosphate (3828-01), and concentrated hydrochloric acid (9535-01) were purchased from J. T. Baker Inc. (Phillipsburg, NJ). Water was distilled in a Barnstead (Boston) glass still (A 1040) and deionized in a Barnstead Nanopore II deionizer (D 3700). The buffer used in all the experiments was $0.02 \mathrm{M}$ $\mathrm{Na}_{2} \mathrm{PO}_{4}$ at $\mathrm{pH}$ 7.5. The membrane chromatography cartridge (CICM10H01) was purchased from Millipore Corporation (Bedford, MA). This cartridge is a stack of cation-exchange membranes with a bed volume of $1.4 \mathrm{~mL}(0.5 \times 1.9 \mathrm{~cm}$ i.d. $)$ and a porosity of 0.825 . The cartridge provides a $1.2-\mu \mathrm{m}$ macroporous network of cellulose modified with carboxymethyl groups with an ion-exchange capacity of about 0.68 meq (manufacturer's data). The 0.22- $\mu \mathrm{m}$ Millex-GV filters (SLGV 025 LS) were purchased from Millipore. Prior to use in experiments, all solutions were filtered using $0.22-\mu \mathrm{m}$ Durapore filters (GVWP 047 00), which were also purchased from Millipore.

\section{METHODS}

\section{Solute Concentration Measurements}

The concentrations of lysozyme and myoglobin were determined by measuring the absorbance at 280 and $410 \mathrm{~nm}$, respectively, whereas the concentrations of $\mathrm{KCl}$ were determined by measuring conductivity on a VWR Scientific Digital Conductivity Meter (model 604). The spectrophotometer used for measuring protein concentration in batch quantities was an HP 8452A diode array spectrophotometer equipped with a cell of path length $10 \mathrm{~mm}$ and chamber volume of $1 \mathrm{~mL}$. The monitors used for continuous measurements of protein concentration were Pharmacia UV-1 monitors equipped with flow cells of path length $10 \mathrm{~mm}$ and chamber volume of $8.7 \mu \mathrm{L}$.

\section{Preferential Transport Apparatus}

The apparatus used to conduct preferential transport separations is shown in Figure 3. The apparatus con- 


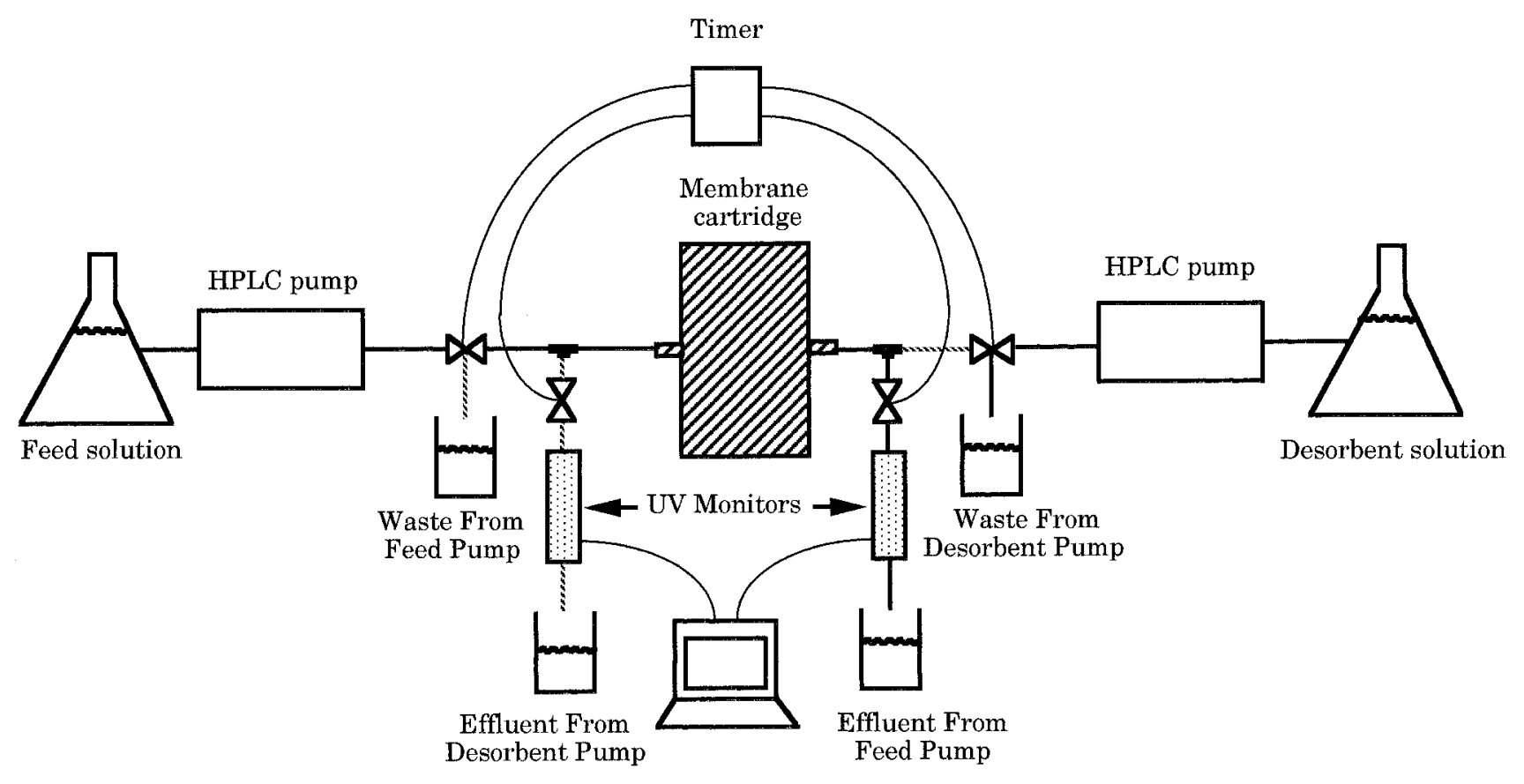

Figure 3. Preferential transport apparatus. During the first half-cycle, feed flows through the membrane and the right UV monitor into a beaker, while the desorbent flow is diverted into a waste beaker (shown by dark lines). During the second half-cycle, desorbent flows through the membrane and past the left UV monitor into a beaker, while the feed flow is diverted into a waste beaker.

sisted of the following: the membrane cartridge, two HPLC pumps (HPX), two 3-way solenoid actuated pinch valves (G-98301-22), two 2-way solenoid actuated pinch valves (G-98301-01), a time delay relay (G-2060230 ) connected to a DC power supply (6284A, Hewlett Packard), two UV monitors connected to a computer, and four beakers. Two $75 \mathrm{psi}(518 \mathrm{kPa})$ back-pressure regulators (P-749), two $100 \mathrm{psi}(690 \mathrm{kPa})$ pressure relief valves (U-456), and two 0-100 psi (0-690 $\mathrm{kPa})$ pressure gauges (9225) were attached in between the HPLC pumps and the 3-way solenoid actuated pinch valves (not shown in Fig. 3). All tubing used in the apparatus was $1 / 16$ in. o.d. The HPLC pumps, back-pressure regulators, and pressure relief valves were purchased from Rainin Instrument Co. (Emeryville, CA). The solenoid valves and the time delay relay were purchased from Cole-Parmer Instrument Co. (Chicago). The pressure gauges were purchased from Alltech Associates, Inc. (Deerfield, IL).

\section{Preferential Transport Experiments}

The membrane, UV monitors, and all the tubing were initially equilibrated with the buffer solution and the desired cycle time was set on the timer. The experiment then proceeded as follows. During the first half-cycle, the feed solution was pumped through the membrane and the right UV monitor into a beaker while the desorbent flow was diverted into a beaker (effectively shutting off the desorbent pump). During the second half-cycle, desorbent was pumped through the membrane and the left UV monitor and into a beaker while the protein flow was diverted to a beaker (effectively shutting off the protein pump). These cycles were continued until there was no change in the amounts of protein collected from one cycle to the next in the two effluent streams.

The experiments described above were conducted under several different conditions, depending on whether the experiment was used to study filtration, integrated separation, or continuous separation. For the integrated separation experiments, the feed solution consisted of lysozyme, myoglobin, and yeast; the membrane system consisted of a $0.22-\mu \mathrm{m}$ Millex-GV filter attached in series onto the feed side of the membrane cartridge. For filtration experiments, the feed solution consisted of yeast and only the $0.22-\mu \mathrm{m}$ Millex-GV filter. In addition, for the filtration experiments peristaltic pumps rather than HPLC pumps were used to generate the oscillatory flows and the UV monitors were disconnected from the apparatus. The Millex-GV filters were discarded after each integrated separation or filtration experiment.

Continuous separation experiments were also conducted in the same way as described earlier except for the following modifications. The reservoirs containing the feed solution and the desorbent solution had flows into and out of each reservoir. Also, the tubes carrying the waste from the feed pump and the effluent from the desorbent pump were immersed into the feed solution reservoir, while the tubes carrying the waste from the desorbent pump and the effluent from the feed pump were immersed into the desorbent solution reservoir. 


\section{Membrane Cartridge Cleaning and Storage}

After each experiment the membrane chromatography cartridge was rinsed with $0.5 \mathrm{M} \mathrm{KCl}$ until there was no detectable protein in the eluent. Typically, this occurred after flowing about $30 \mathrm{~mL}$ of $0.5 \mathrm{M} \mathrm{KCl}$. At the end of the day, the membrane cartridge was flushed with 25 $\mathrm{mL}$ distilled and deionized water and then with $10 \mathrm{~mL}$ of a $0.02 \%$ sodium azide solution in deionized water before storage at $4^{\circ} \mathrm{C}$.

\section{RESULTS AND DISCUSSION}

In an earlier study on a semicontinuous apparatus (Agrawal and Burns, 1996b), we found that by using preferential transport, lysozyme is selectively removed from a mixture of lysozyme, myoglobin, and yeast cells (Fig. 4). Note that the membrane system used for the separation shown in Figure 4 consisted of a $0.22-\mu \mathrm{m}$ filter placed in series with the ion-exchange membrane cartridge. We found that this decoupling of the filtration and selective transport operations increased the lifetime of the adsorptive membrane cartridge without significantly affecting the flux of solute; for the preferential transport of lysozyme, experiments with and without the $0.22-\mu \mathrm{m}$ filter produced similar results.

This study explores two specific areas of this separation system. First, the effect of the oscillatory flow on solute and convective flux in the presence of suspended cells and the ability of this type of flow to alleviate cake formation is investigated. Second, design considerations for a continuous separation system based on preferential

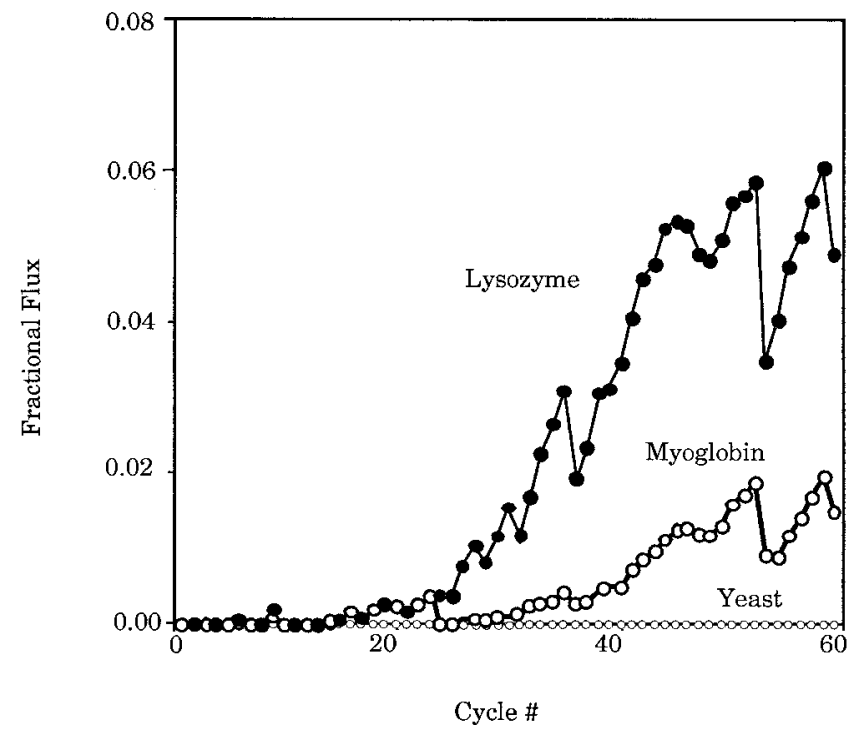

Figure 4. Semicontinuous integrated separation. Preferential transport through adsorptive membranes leads to simultaneous adsorptionbased and size-based separation. Lysozyme, the adsorbing protein, can be continuously removed from a mixture of lysozyme, myoglobin (the nonadsorbing protein), and yeast cells. Note that coherence is obtained in approximately 50 cycles. transport are investigated to determine the quality of separation that can be obtained. It is important to note that although two different membranes were used in this study, the membrane filter and the membrane cartridge, the results of this study also apply to a single adsorptive membrane stack designed for processing feeds containing suspended particles.

\section{Filtration with Oscillatory Flow}

Filtration with oscillatory flow involves asymmetric strokes in which a volume of feed solution $\left(V_{\mathrm{s}, \mathrm{a}}\right)$ containing suspended particles is fed into a membrane followed by a volume of particle-free solution $\left(V_{\mathrm{s}, \mathrm{d}}\right)$ fed in the reverse direction. The reverse stroke removes the suspended particles that may have collected on the membrane surface during the forward stroke, thereby alleviating cake formation. This phenomenon has been shown in previous work and is illustrated by the results shown in Figure 5. When a solution containing 1\% dry weight yeast is filtered with unidirectional flow (or $V_{\mathrm{s}, \mathrm{a}} / V_{\mathrm{s}, \mathrm{d}}=$ infinity), the pressure drop across the membrane increases very rapidly. In contrast, when oscillatory asymmetric strokes are used with $V_{\mathrm{s}, \mathrm{a}} / V_{\mathrm{s}, \mathrm{d}}=4$, the rate of increase in pressure drop is significantly less. During oscillatory flow, the effect of shear rate tangential to the membrane surface on the pressure drop across the membrane is small relative to the effect of parameters such as the ratio of forward to reverse strokes $\left(V_{\mathrm{s}, \mathrm{a}} / V_{\mathrm{s}, \mathrm{d}}\right)$.

Oscillatory flow filtration and preferential transport both rely on an oscillatory flow field to enhance the

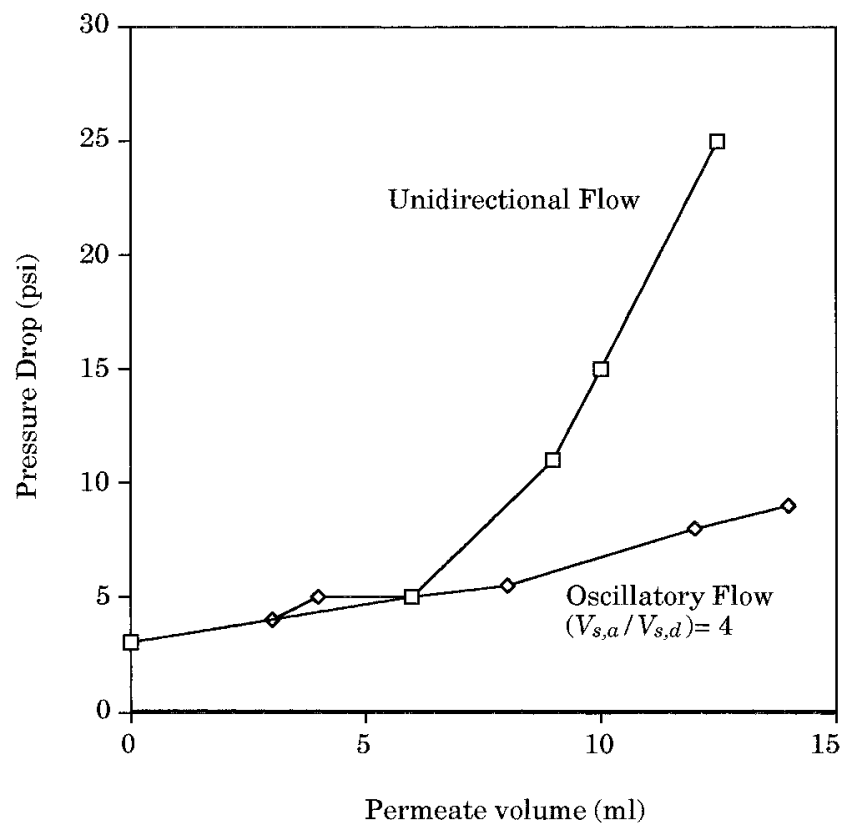

Figure 5. Oscillatory flow alleviates cake formation. When an oscillatory flow is used, the increase in pressure drop per volume of permeate is lower than that for unidirectional flow. 
performance. Therefore, we can apply the cake-reducing technology of oscillatory filtration with the selective extraction properties of preferential transport to form an integrated separation process. The most significant difference when considering combining these two systems is found in the magnitude of $V_{\mathrm{s}, \mathrm{a}} / V_{\mathrm{s}, \mathrm{d}}$. In typical oscillatory flow filtration studies, the ratio of the forward stroke to the reverse stroke is on the order of 10-100 (Redkar and Davis, 1995). On the other hand, in preferential transport this ratio is on the order of 1 (a typical value is 1.02; Agrawal and Burns, 1996a).

In preferential transport, the low net convective flux through the membrane allows large volumes of solution to be processed (i.e., fed to the membrane unit) without dramatically increasing the pressure drop across the membrane. This fact is illustrated in Figure 6; the figure includes the data shown in Figure 5 except that the data is expressed in terms of processed volume rather than permeate volume. Figure 6 shows that even with $V_{\mathrm{s}, \mathrm{a}} / V_{\mathrm{s}, \mathrm{d}}=4$, the rate of increase of pressure drop is large $(\approx 0.25 \mathrm{psi} / \mathrm{mL}, 1.73 \mathrm{kPa} / \mathrm{mL})$. On the other hand, when $V_{\mathrm{s}, \mathrm{a}} / V_{\mathrm{s}, \mathrm{d}}=1$, the rate of increase in pressure drop is drastically lower $(\approx 0.01 \mathrm{psi} / \mathrm{mL} ; 0.07 \mathrm{kPa} / \mathrm{mL})$, implying that with $V_{\mathrm{s}, \mathrm{a}} / V_{\mathrm{s}, \mathrm{d}}=1$, large volumes of cell-containing solutions can be processed. Note that this "processing" refers to selective extraction and not total cell filtration; for solute recovery with efficient extraction, cell removal is not necessary.

Using oscillations in which the forward stroke volume is close to the reverse stroke volume, we can process solutions that contain high cell concentrations. Figure

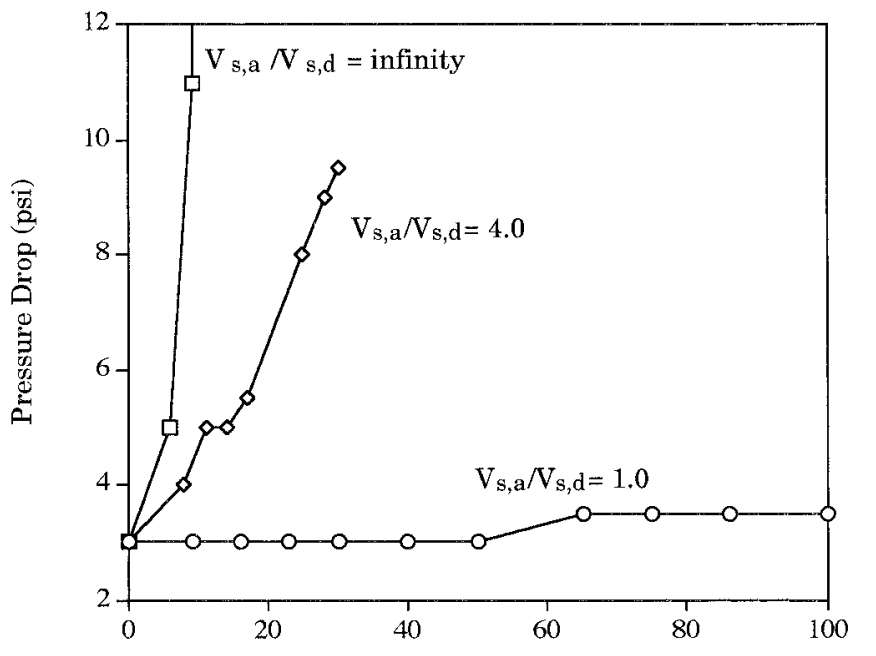

Volume Processed (ml)

Figure 6. Feed processing capacity. As $V_{\mathrm{s}, \mathrm{a}} / V_{\mathrm{s}, \mathrm{d}}$ is decreased, the rate of increase in pressure drop is much slower. Additionally, when $V_{\mathrm{s}, \mathrm{a}} / V_{\mathrm{s}, \mathrm{d}}=1$, the rate of increase in pressure drop is almost negligible, implying that with $V_{\mathrm{s}, \mathrm{a}} / V_{\mathrm{s}, \mathrm{d}}=1$ large volumes of cell-containing solutions can be processed. For this plot, cell concentration $=10 \mathrm{mg} / \mathrm{mL}$ ( $1 \%$ dry weight $)$, flow rate $=5.1 \mathrm{~mL} / \mathrm{min}$, cycle time $=20 \mathrm{~s}$.
7 shows experimental results in which solutions of $1-$ $10 \%$ dry weight yeast were processed using oscillatory flows with $V_{\mathrm{s}, \mathrm{a}} / V_{\mathrm{s}, \mathrm{d}}=1$. As expected, the pressure drop across the membrane increases with increasing cell concentration. However, for all cell concentrations, the increase in pressure drop is not substantial. For the highest cell concentration studied, the pressure drop rapidly increases to 7 psi (48 $\mathrm{kPa}$ ), but after reaching 7 psi the rate of increase is low. The slow rate of increase suggests that a relatively large volume of solution containing $10 \%$ cells could be processed by preferential transport. Note for comparison that the oscillatory flows used in filtration studies are typically conducted with $1 \%$ cell solutions (Redkar and Davis, 1995).

In addition to $V_{\mathrm{s}, \mathrm{a}} / V_{\mathrm{s}, \mathrm{d}}$ and cell concentration, another important variable that controls the rate of increase in pressure drop is the amplitude of the oscillations $\left(V_{\mathrm{s}, \mathrm{a}}\right)$. Figure 8 shows that the rate of increase of pressure drop increases as the amplitude of oscillations increases. For example, for a processed volume of $60 \mathrm{~mL}$, for $V_{\mathrm{s}, \mathrm{a}}=$ $5.1 \mathrm{~mL}$, the pressure drop increase is $9 \mathrm{psi}(62 \mathrm{kPa})$; for $V_{\mathrm{s}, \mathrm{a}}=0.85 \mathrm{~mL}$, the increase is only $0.5 \mathrm{psi}(3.4 \mathrm{kPa})$. The amplitude of oscillation $\left(V_{\mathrm{s}, \mathrm{a}}\right)$ is important in preferential-transport separations because for a given system there is an optimum ratio of oscillation amplitude to membrane void volume $\left(V_{\mathrm{s}, \mathrm{a}} / V_{\mathrm{m}}\right)$ that leads to maximum adsorbing solute flux (Agrawal and Burns, 1996a).

Filtration experiments were conducted with feed solutions containing lysozyme and myoglobin in addition to cells. These experiments were conducted because past studies (Marshall et al., 1993) indicated that membrane fouling can occur by adsorption or precipitation (Bel-

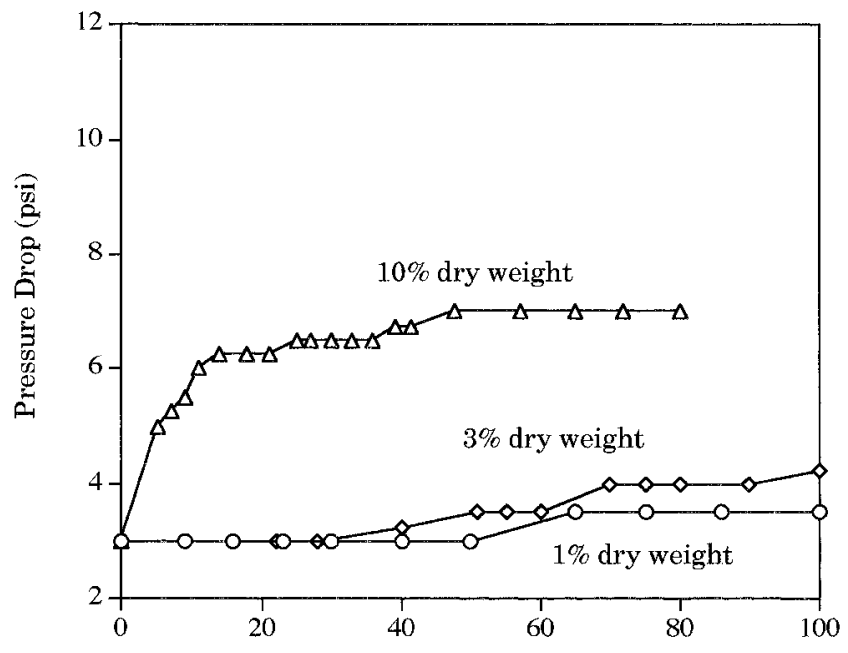

Volume Processed (ml)

Figure 7. Effect of cell concentration. Using oscillations in which $V_{\mathrm{s}, \mathrm{a}} / V_{\mathrm{s}, \mathrm{d}} \approx 1$, higher cell concentrations can be processed. For example, for $10 \%$ cells the pressure drop is only 7 psi and its slow rate of increase suggests that a large volume of cell solution can also be processed. For these experiments, $V_{\mathrm{s}, \mathrm{a}} / V_{\mathrm{s}, \mathrm{d}}=1.0$, cycle time $=20$, feed flow rate $=5.1 \mathrm{~mL} / \mathrm{min}$. 


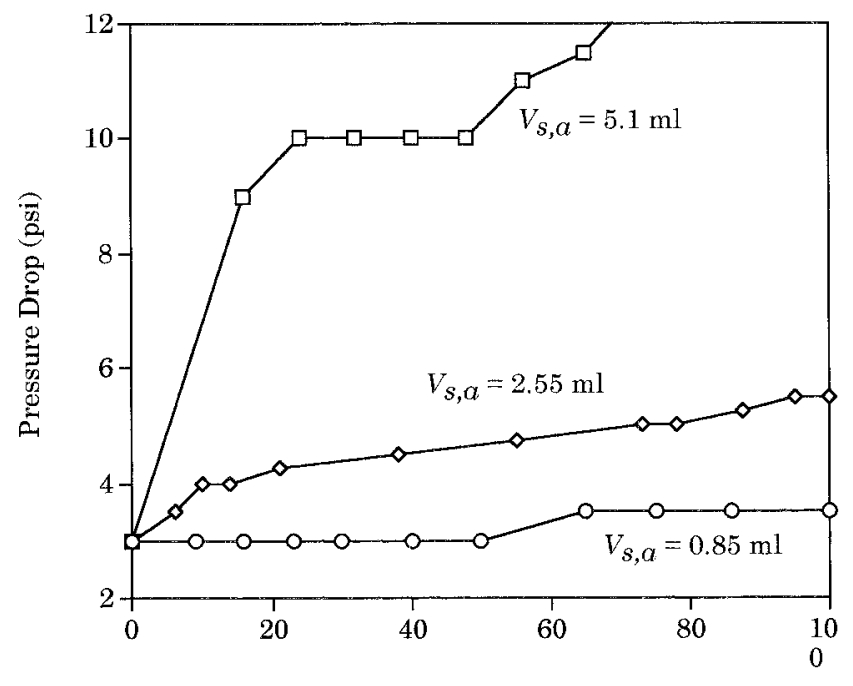

Volume Processed (ml)

Figure 8. Effect of amplitude of oscillations. Increase in pressure drop is lower at lower amplitudes of oscillations $\left(V_{\mathrm{s}, \mathrm{a}}\right)$. For example, for a processed volume of $60 \mathrm{~mL}$, the increase in pressure drop is about 9 psi $(62 \mathrm{kPa})$ at $V_{\mathrm{s}, \mathrm{a}}=5.1 \mathrm{~mL}$, while the increase in pressure drop is only $0.5 \mathrm{psi}(3.4 \mathrm{kPa})$ at $V_{\mathrm{s}, \mathrm{a}}=0.85 \mathrm{~mL}$. For this plot, cell concentration $=10 \mathrm{mg} / \mathrm{mL}(1 \%$ dry weight $), V_{\mathrm{s}, \mathrm{a}} / V_{\mathrm{s}, \mathrm{d}}=1.0$, cycle time $=20 \mathrm{~s}$, flow rate $=5.1 \mathrm{~mL} / \mathrm{min}$

fort, 1989). Our experiments with lysozyme and myoglobin showed that the increase in pressure drop due to fouling by adsorption or precipitation is small relative to the increase in pressure drop due to yeast. For example, upon filtering $100 \mathrm{~mL}$ of solution containing lysozyme and myoglobin without cells, we found that pressure drop increased by only 2 psi $(13.8 \mathrm{kPa})$. On the other hand, upon filtering $100 \mathrm{~mL}$ of the solution containing cells and protein, we found that pressure drop increased by 16 psi $(110 \mathrm{kPa})$. These results suggest preferential transport can be used for the continuous separation of a single protein from a solution that contains other proteins as well as cells.

\section{Process Variables Affecting Continuous Separation}

The semicontinuous apparatus shown in Figure 3 was converted to a continuous apparatus similar to that shown in Figure 2 (see Materials and Methods). Our previous studies (Agrawal and Burns, 1996a,b) focused on the internal phenomena occurring in preferential transport [described by Equations (1)-(4)] and determined the effects of process variables, such as stroke volumes and solute concentrations on either side of the membrane, on the flux of solutes through the membrane. Our previous studies also showed that theoretical results obtained from the internal mass balances agreed with experimental results and that they predict the optimal values for the ratio of stroke volume to membrane void volume $\left(V_{\mathrm{s}} / V_{\mathrm{m}}\right)$ and the ratio of adsorbing stroke volume to the desorbing stroke volume $\left(V_{\mathrm{s}, \mathrm{a}} / V_{\mathrm{s}, \mathrm{d}}\right)$. This section focuses on examining a continuous contactor [described by Equations (5)-(18)] that uses preferential transport and presents the effects of process variables, such as flows into and out of the reservoirs and the reservoir volumes, on the quality of the separation obtained.

The effects of process variables on the continuous separation are measured in terms of concentration, selectivity, and recovery. Concentration is defined as the ratio of the concentration of adsorbing solute in the right product stream to that in the feed stream. Selectivity is defined as the ratio of the amount of adsorbing solute issuing from the right reservoir to the amount of nonadsorbing solute issuing from the right reservoir. Finally, recovery is defined as the ratio of the amount of adsorbing solute contained in the right product stream to the amount of adsorbing solute fed into the left reservoir. It is important to note that this definition of recovery is a percent removal rather than recovery in the classical sense, because recovery here implies the amount fed minus the amount recycled.

Perhaps the most interesting theoretical result that we obtained is that, by using a low desorbent flow rate, the adsorbing solute can be obtained in a concentrated product stream. In other words, the concentration of the adsorbing solute in the product stream can be higher than that in the feed stream. Figure 9 shows that when the dimensionless desorbent flow rate $\left(q_{\mathrm{d}} / q_{0}\right)$ is about 0.01 , a product stream about 2.5 times as concentrated as the feed stream in the selectively transported solute is obtained. Additionally, if the media has a Peclet number $(\mathrm{Pe})$ of $2 \times 10^{4}$, a product stream about 7 times as

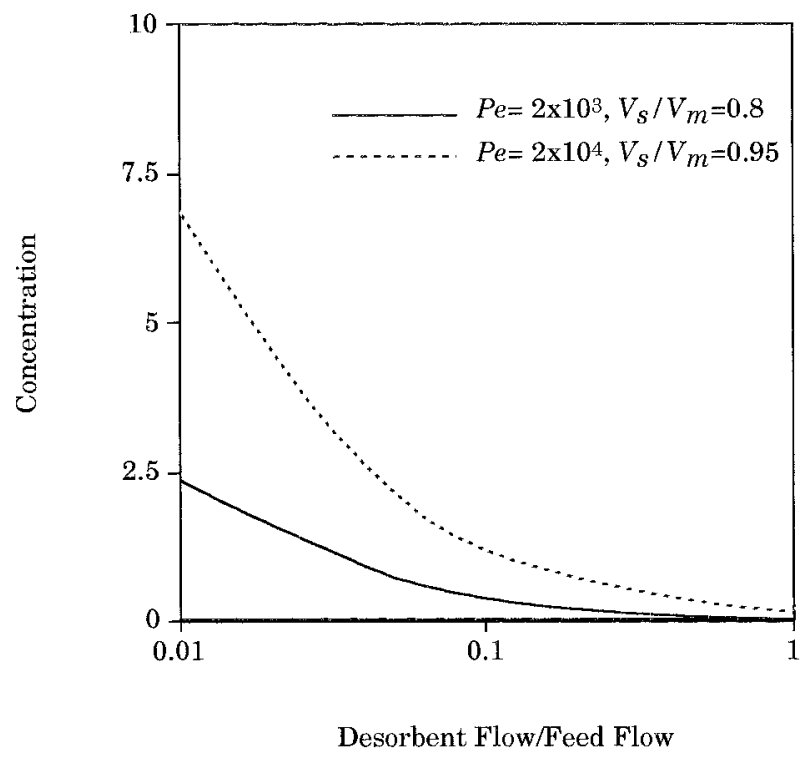

Figure 9. Effect of desorbent flow. Using low desorbent flow rates, we can obtain a continuous concentrated stream of the adsorbing solute. All parameters used to generate this figure are given in Table I. 
concentrated as the feed stream is obtained. Note that for $\mathrm{Pe}=2 \times 10^{4}$, the value of $V_{\mathrm{s}} / V_{\mathrm{m}}$ was kept at 0.95 rather than 0.8 because as Pe increases, the optimum value of $V_{\mathrm{s}} / V_{\mathrm{m}}$ that gives the highest adsorbing solute flux also increases (Agrawal and Burns, 1996a).

To obtain a concentrated stream, the desorbent concentration fed into the right reservoir must be adjusted so that the concentration in the right reservoir is close to the optimal concentration. For example, for $q_{\mathrm{d}} / q_{0}=$ 0.01 , the concentration of $\mathrm{KCl}$ fed continuously into the right reservoir was $1.05 \mathrm{M}$ so that the concentration in the right reservoir was maintained close to the optimal 0.35M. We showed earlier (Agrawal and Burns, 1996b) that an optimal concentration exists, because at high desorbent concentration the entire membrane is nonadsorbing; alternatively, for low desorbent concentration the entire membrane is adsorbing. The appropriate desorbent concentration fed into the right reservoir can be determined a priori by conducting a simple mass balance on the right reservoir.

It is important to note that the backflux of desorbent from the right to the left side of the membrane would eliminate any concentration effect. However, the concentration of the product in the separations discussed above is possible because there is negligible backflux of the desorbent; i.e., there is negligible flux of desorbent from the right reservoir to the left reservoir. The concentration of $\mathrm{KCl}$ in the left reservoir is only between $10^{-4}$ and $10^{-6}$ times the concentration of desorbent fed to the right reservoir. The negligible backflux of desorbent is advantageous because it does not lower the membrane capacity. Additionally, because of negligible backflux, the required volume of desorption buffer could be reduced by recycling the desorbent to the right reservoir in the configuration shown in Figure 2.

This concentration of solute in the product stream obtained at low desorbent flow rates does not affect the selectivity and recovery significantly. For the simulation results shown in Figure 9 in which the dimensionless oscillatory flow was fixed, the selectivity for $\mathrm{Pe}=10^{3}$ was 2.5 , while the recovery was $5 \%$; also, the selectivity for $\mathrm{Pe}=10^{4}$ was 6.8 and the recovery was $13 \%$.

Higher recoveries can be obtained by using high dimensionless oscillatory flow rates (Fig. 10). For example, by using a dimensionless oscillatory flow (oscillatory flow/feed flow) of about 10, the recovery is about $39 \%$. Also, for $\mathrm{Pe}=2 \times 10^{4}$, recovery is much higher $(\sim 61 \%)$. Note that the high recoveries obtained at the high oscillatory flows come with a slight decrease in selectivity. For example, for $\mathrm{Pe}=2 \times 10^{4}$, as we increase $q_{\mathrm{s}} / q_{0}$ from 0.1 to 10 , recovery increases from 1.6 to $61 \%$, while the selectivity decreases from 8.0 to 3.7. Therefore, the ratio $q_{\mathrm{s}} / q_{0}$ has to be optimized according to process requirements.

Figures 9 and 10 show that higher concentration, selectivity, and recovery can be obtained by using media that have a higher Peclet number than the membrane

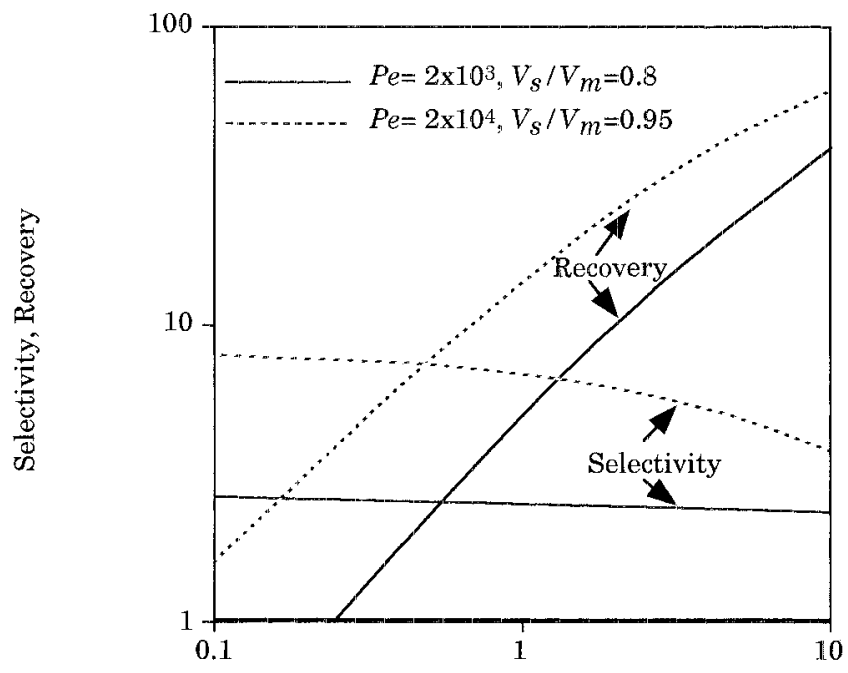

Oscillatory Flow/Feed Flow

Figure 10. Effect of oscillatory flow. High recoveries can be obtained using high oscillatory flows. However, as the oscillatory flow is increased, a lower selectivity is obtained; therefore, the oscillatory flow has to be optimized according to process requirements. All parameters used to generate this figure are given in Table I.

cartridge used in this study. Packed beds typically have Peclet numbers that are higher than adsorptive membranes (Coffman et al., 1994) and are in the range $3 \times$ $10^{4}$ to $10^{6}$ (Phillips et al., 1988). Therefore, packed beds could lead to better separations than adsorptive membranes. A packed bed can also be used in an integrated separation process by attaching a filter in series with the packed bed so that the cells do not clog the bed. However, such a filter can be expected to increase the dispersion in the packed bed but will not significantly affect the separation. To estimate this increased dispersion effect, we modeled the filter as a continuously stirred tank reactor (worst case). From our modeling results we found that as long as the filter volume is less than $1 \%$ of the packed bed volume, there is negligible decrease in the adsorbing solute fractional flux and a negligible increase in the nonadsorbing solute fractional flux.

The dimensionless left and right reservoir volumes do not affect recovery, selectivity, or concentration significantly. However, the dimensionless reservoir volumes significantly affect the number of oscillations taken to attain coherence. For example, the number of oscillations taken to attain coherence is about 35 when $V_{\mathrm{L}} / V_{\mathrm{m}}$ is 1 and about 70 when $V_{\mathrm{L}} / V_{\mathrm{m}}$ is $20\left(q_{\mathrm{s}} / q_{0}=1\right.$, $q_{\mathrm{d}} / q_{0}=0.1, V_{\mathrm{R}}^{0} / V_{\mathrm{m}}=1$, all other parameters are given in Table I) implying that the time taken to attain coherence can be kept small by keeping the dimensionless reservoir volumes as low as possible. Commercially obtained membranes can be stacked so that membrane void volumes can easily be on the order of $10 \mathrm{~mL}$; 
Table I. Typical parameters.

\begin{tabular}{ll}
\hline Experimental parameters & \\
Lysozyme concentration in feed & $C_{A, 0}=4.0 \mathrm{mg} / \mathrm{mL}$ \\
Ionic strength desorbent stream & $C_{D, 0}=0.37 M$ \\
Ratio of & $q_{\mathrm{s}} / q_{0}=1$ \\
$\quad$ Oscillatory flow to feed flow & $q_{\mathrm{d}} / q_{0}=0.2$ \\
$\quad$ Desorbent flow to feed flow & $V_{\mathrm{L}}^{0} / V_{\mathrm{m}}=4.0$ \\
Initial left reservoir vol. to & $V_{\mathrm{R}}^{0} / V_{\mathrm{m}}=4.0$ \\
$\quad$ membrane void vol. & $V_{\mathrm{s}} / V_{\mathrm{m}}=0.8$ \\
Initial right reservoir vol. to & $V_{\mathrm{s}, \mathrm{a}} / V_{\mathrm{s}, \mathrm{d}}=1.02$ \\
$\quad$ membrane void vol. & \\
Stroke vol. to membrane void vol. & $V_{\mathrm{m}}=1.16 \mathrm{~mL}$ \\
Adsorbing stroke vol. to desorbing & $\mathrm{Pe}=2100$ \\
$\quad$ stroke vol. & $K_{\mathrm{m}}^{\max }=69.8 \mathrm{~mL} / \mathrm{mg}$ \\
Parameters determined independently & $Q_{\mathrm{m}}^{\max }=18.2 \mathrm{mg} / \mathrm{mL}$ \\
Membrane void vol. & \\
Peclet number & \\
Equilibrium constant at $0 M$ KCl & $f=0.0024 * I^{-1.55}$ \\
Membrane saturation capacity at & \\
$\quad 0 M$ KCl & $g=0.0046 * I^{-1.38}$ \\
Function relating & \\
Equilibrium constant to ionic & \\
$\quad$ strength &
\end{tabular}

Unless otherwise indicated, these parameters were used in all experiments and simulations.

therefore, the reservoir volumes should be set at 1-100 $\mathrm{mL}$, values that are plausible.

Modeling results were used to chose parameters for the experimental continuous separations. The desorbent flow to feed flow ratios were fixed at low values $(\approx 0.1)$ in order to give a concentrated product stream (Fig. 9). These values, however, were still much higher than the desired values $(<0.01)$, which could not be obtained due to limitations in the available equipment. The oscillatory flow to feed flow ratio was fixed at a value of 1 in order to give high selectivity and recovery (Fig. 10). The reservoir volume to membrane void volume was fixed at 4 , which was the lowest practical value in our setup.

Figure 11 shows a typical experimental result in which lysozyme was continuously removed from a mixture of lysozyme and myoglobin. The flux of lysozyme at steady state is $1.94 \mathrm{mg} / \mathrm{h} / \mathrm{cm}^{2}$ and the selectivity of the separation at steady state is 11.4. These experimental measurements were found to be reproducible within experimental error. Note that for the results shown in Figure 11, the concentration of lysozyme obtained in the product stream was low (about $2 \%$ of feed concentration). In a separate experiment we found that the concentration of lysozyme was increased 3 times by using a lower desorbent flow rate (20\% of that used in Fig. 11). A comparison of these results with theoretical predictions showed qualitative but not quantitative agreement, most likely due to the limitations of our experimental apparatus.

\section{CONCLUSIONS}

Preferential transport can lead to an integrated separation process that combines the steps of filtration, adsorption, and desorption. This integrated process was used to separate lysozyme directly from a feed containing lysozyme, myoglobin, and yeast. In separate experiments we found that because the oscillatory flows used in preferential transport involve strokes that are close

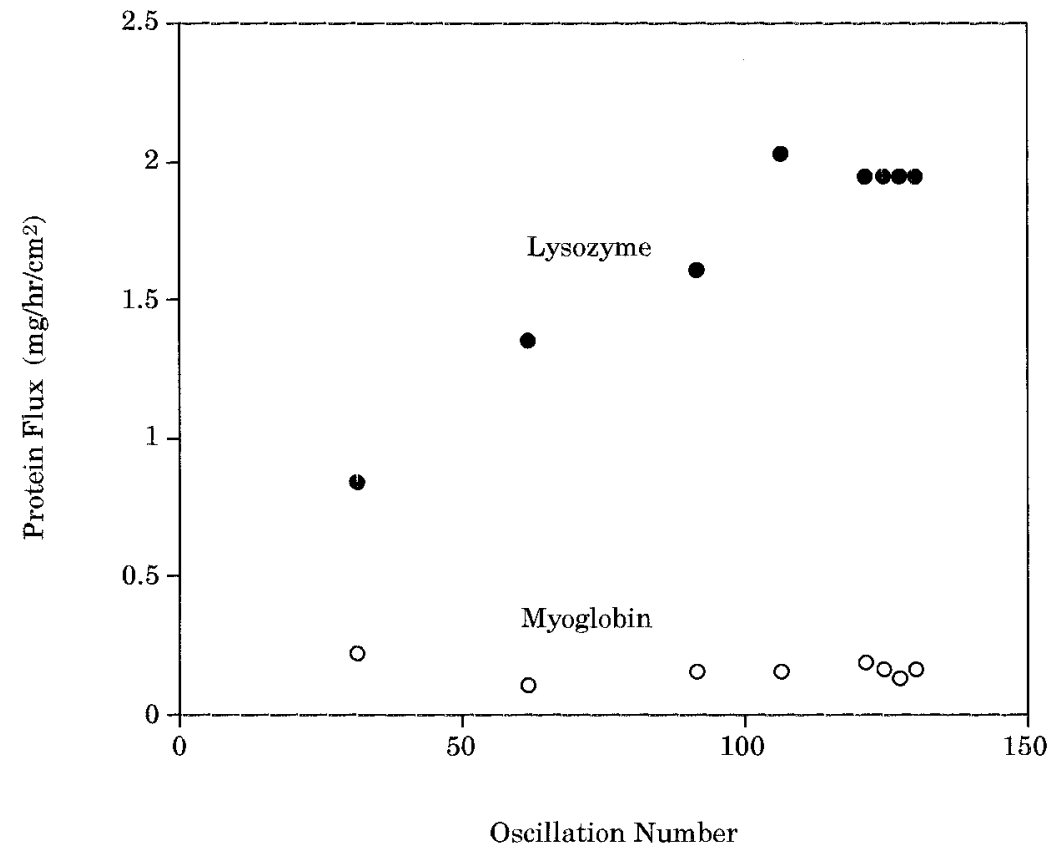

Figure 11. Continuous separation: typical experimental results. Lysozyme is continuously and selectively removed from a mixture of lysozyme and myoglobin. 
to symmetric (forward and reverse stroke volumes are similar in magnitude), they are very efficient in alleviating cake formation.

Theoretical results suggest that continuous preferential transport can lead to high selectivity and recovery if the ratio of the oscillatory flow to feed flow is optimized. Additionally, by using low desorbent flows a concentrated stream of the adsorbing solute can be obtained. A possible application of continuous preferential transport is in situ product removal. For example, preferential transport can be used to continuously remove a toxin from a fermentation broth using an affinity membrane specific to the toxin with the treated feed being recycled back to the broth (see Fig. 2).

This work was partially funded by the National Science Foundation (CTS-9216078 and CTS-9096185) and the University of Michigan.

\section{NOMENCLATURE}

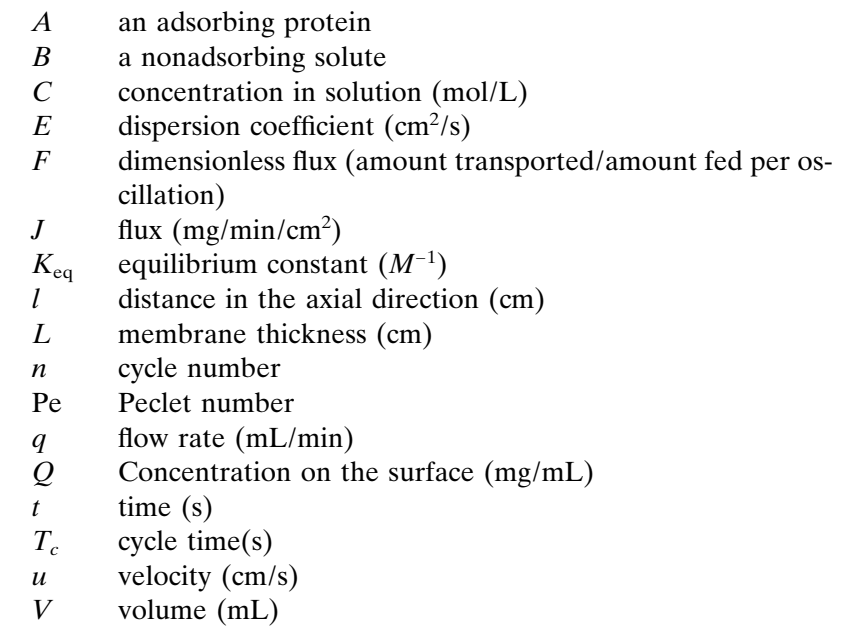

\section{Subscripts}

feed

adsorbing

desorbing

a nonadsorbing solute

left

right

membrane

max maximum

s stroke
Greek letters

$\alpha \quad$ affinity parameter of the Langmuir isotherm (dimensionless)

$\delta$ feed concentration/maximum capacity

$\varepsilon \quad$ membrane porosity

$\eta \quad$ frequency of oscillations

\section{References}

Agrawal, A., Burns, M. A. 1996a. Recuperative parametric pumping in adsorptive membranes. AIChE J. 42: 131-146.

Agrawal, A., Burns, M. A. 1996b. Selective extraction using preferential transport through adsorptive membranes. Biotechnol. Bioeng. 52: $539-548$.

Anita, F. D., Horvath, C. 1989. Gradient elution in non-linear preparative liquid chromatography. J. Chromatogr. 484: 1-27.

Belfort, G. 1989. Fluid mechanics in membrane filtration: Recent developments. J. Memb. Sci. 40: 123-147.

Coffman, J. L., Roper, D. K., Lightfoot, E. N. 1994. High-resolution chromatography of proteins in short columns and adsorptive membranes. Bioseparation 4: 183-200.

Freeman, A., Woodley, J. M., Lilly, M. D. 1993. In situ product removal as a tool for bioprocessing. Bio/Technology 11: 1007-1012.

Grevillot, G. 1986. Principles of parametric pumping. Handbook for heat and mass transfer operations volume 2. Gulf Publishing, West Orange, NJ.

Huang, C.-R., Hollein, H. C. 1988. Parametric pumping. Handbook of separation techniques for chemical engineers. McGraw-Hill, New York.

Kroner, K. H., Schutte, H., Hustedt, H., Kula, M. R. 1984. Cross-flow filtration in the downstream processing of enzymes. Proc. Biochem. 67.

Marshall, A. D., Munro, P. A., Tragardh, G. 1993. The effect of protein fouling in microfiltration and ultrafiltration on permeate flux, protein retention and selectivity: A literature review. Desalination 91: $65-108$.

Matsumoto, K., Katsuyama, M., Ohya, H. 1987. Separation of yeast by cross-flow filtration with back-washing. J. Ferment. Technol. 65: 77.

Phillips, M. W., Subramanian, G., Cramer, S. M. 1988. Theoretical optimization of operating parameters in non-ideal displacement chromatography. J. Chromatogr. 454: 1-21.

Redkar, S. G., Davis, R. H. 1995. Cross-flow microfiltration with highfrequency reverse filtration. AIChE J. 41: 501-508.

Sweed, N. H., Rigaudeau, J. M. 1975. Adsorption and ion exchange. AIChE Symp. Ser. 71: 1-5.

Wankat, P. C. 1978. Continuous recuperative mode parametric pumping. Chem. Eng. Sci. 33: 723-733.

Wilhelm, R. H., Rice, A. W., Bendelius, A. R. 1966. Parametric pumping: A dynamic principle for separating fluid mixtures. Ind. Eng. Chem. Fund. 5: 141-144. 